\title{
Application of the new Morphological Quality Index in the Cordevole river (BL, Italy)
}

\author{
E. Rigon, J. Moretto, F. Delai, L. Picco, D. Ravazzolo, R. Rainato, M.A. Lenzi \\ Department of Land, Environment, Agriculture and Forestry, University of Padova, Italy
}

\begin{abstract}
The evaluation of the morphological quality of rivers is essential to define the level of alteration and for implementing future management strategies that consider also hazards related to fluvial processes and channel dynamics. This type of evaluation is particularly significant for the Italian rivers, that, as in many other European countries, have a very high level of human pressure. Recently, in Italy, the National Institute for Environmental Protection and Research has promoted a methodology named IDRAIM for hydromorphological analysis of streams that pursues an integrated approach aimed at a harmonized implementation of both the EU Water Framework Directive (WFD, 2000/60/EC), and the EU Floods Directive (2007/60/EC). In this paper we present the application of the Morphological QualityIndex (MQI) protocol, which is part of IDRAIM, to determine the assessment of the morphological quality of the Cordevole River. The water network (only collectors greater than thirdorder were considered), has been divided, through GIS software, into 132 river reaches of homogeneous morphological characteristics, according to the first phase of the method. At this stage the semi-automatic calculation of lateral confinement (defined by "degree of confinement" and a "confinement index") was tried, in order to reduce the implementing time. The application of 28 indicators was made for 42 reaches representing the major river types and human pressures in the site investigation. The results showed that $48 \%$ of the analyzed reaches have a very good or good quality status, 38\% have a moderate morphological quality, while only $14 \%$ have the characteristics of poor or very poor quality. The main
\end{abstract}

Correspondence: Emanuel Rigon, Department of Land, Environment, Agriculture and Forestry, University of Padova, Italy.

E-mail: emanuel.rigon@unipd.it

Key words: Hydromorphology, river network segmentation, morphological recovery, Water Framework Directive, Cordevole River (Bl, Italy).

Acknowledgments: this research was founded by both the University of Padua Strategic Research Project PRST08001, "GEORISKS, Geological, morphological and hydrological processes: monitoring, modelling and impact in North-Eastern Italy", Research Unit STPD08RWBY-004 and the Project "SedAlp": sediment management in Alpine basins, integrating sediment continuum, risk mitigation and hydropower", 83-4-3-AT, in the framework of the European Territorial Cooperation Programme "Alpine Space" 2007-2013.

(C) Copyright E. Rigon et al., 2013

Licensee PAGEPress, Italy

Journal of Agricultural Engineering 2013; XLIV(s2):e9

doi:10.4081/jae.2013.s2.e9

This article is distributed under the terms of the Creative Commons Attribution Noncommercial License (by-nc 3.0) which permits any noncommercial use, distribution, and reproduction in any medium, provided the original author(s) and source are credited. causes that lead to a strong alteration of the terms of reference are linked to i) poor connectivity between hillslopes and river corridor, that is very important for the natural supply of sediment and large wood; ii) absence of vegetation in the river corridor, that is functional to a range of geomorphic processes; iii) presence of artificial elements, particularly the bedload interception structures in the catchment, bank protection along the reach, and the removal of sediment, large wood and vegetation.

\section{Introduction}

Many European rivers suffered different ranges and types of human pressure that modified their morphology and altered their hydrological processes (Liébault and Piégay, 2001; Gurnell et al., 2009). In the recent years, it was necessary to have a tool to assess the ecological, morphological, hydrological conditions and the alteration level respect the reference conditions of rivers. The main purpose of this tool is to define strategies of morphological recovery and plan river restoration management. The EU Water Framework Directive (WFD; European Commission, 2000) and EU Floods Directive (European Commission, 2007), defines a series of innovative criteria and actions necessary for the ecological classification and management of European rivers. The WFD introduces the term "hydromorphology", which requires the consideration of any modifications of flow regime, sediment transport, river morphology, and lateral channel mobility.

The evaluation of the hydromorphological quality is particularly significant for the Italian rivers, that, as in many other European countries, have a very high level of human pressure (e.g. Surian et al., 2009; Rigon et al., 2012b; Moretto et al., 201). The National Institute for Environmental Protection and Research (ISPRA) has recently promoted a new and innovative methodology for the hydromorphological evaluation, analysis, and monitoring of Italian streams (IDRAIM). In this paper we present the application of the Morphological Quality Index (MQI) protocol, which is part of IDRAIM, (Rinaldi et al., 2013) in the Cordevole River, a main tributary of the Piave River. The first phase of the MQI procedure (general setting and segmentation) was implemented for the whole catchment area and was classified by remote sensing with GIS techniques in 132 segments between the sixth and fourth order. The 28 indicators contained in the evaluation forms were applied in second phase for 42 reaches, about $30 \%$ of the total river network. In addition, we propose a methodology for the semi-automatic calculation of lateral confinement (defined by "degree of confinement" and a "confinement index"), in order to reduce the time of river network segmentation.

\section{Study area}

The Cordevole river (Figure 1) has a length of about $79 \mathrm{~km}$, entirely within the province of Belluno (Italy north-east). It rises at the 
Pordoipass (1919 m a.s.l.), in the municipality of "Livinallongo del Col di Lana" and flows into the Piave river near the town of Mel, ( $275 \mathrm{~m}$ a.s.l.). The major tributaries are the Fiorentina and Pettorina (near Caprile), the Biois (Cencenighe) and Tegnas (Taibon). Downstream of Agordo the stream continues along a narrow valley where sometimes remains dry, due to the hydroelectric derivations. A few kilometers from the mouth receives the Mis stream.

The catchment area (Figure 1), which accounts for $843 \mathrm{Km}^{2}$ (hydro GIS analysis, see below), has a mountainous planform, and gives to the hydrographic network a tormented morphology typical of Alpine basins. Woodlands cover about $40 \%$ of the territory, and are mainly spruce, and the local climate is very influenced by altitude and exposure (mean annual temperature is $\approx 7^{\circ} \mathrm{C}$ and mean annual precipitation is $\approx 1100$ $\mathrm{mm})$.

The geology of the area is very complex . The higher parts of the basin are generally composed of dolomite, limestone, and volcanic rocks forming subvertical cliffs, whereas the lower slopes, deeply incised by rivers, are formed by highly erodible sedimentary rocks and quaternary deposits, with diffuse mass wasting processes (Picco et al., 2012)

The flow regime (contributions from rain and snowmelt) has a high runoff during the months of May-June and low flows during the months of January-February (colder months). In the autumn often occur intense and short duration rains, causing flash flood. Part of the territory of the basin lies within the Belluno Dolomites National Park and there are several natural areas and landscapes of Regional interest.

The artificial interventions (check-dams, transversal and crossing structures, bank protections) are very present in the stream and are located near population centers and roads. Many of these interventions were built in the years following the 1966 flood that showed how these areas can be dangerous. There are mainly transversal structures and check-dams very large and close-ups, now filled with sediment, and thus no longer functional. In the recent years there is a tendency to naturalistic intervene, but overall the interventions are few and only built in cases of extreme necessity for the hydrogeological safety. The interventions for hydroelectric power production, already designed in the 1930 for the presence of two natural basins (Marmolada Glacier and Alleghe Lake) are mainly represented by the Masarè spillway (Alleghe), the Ghirlo dam (Cenceninghe) and the Mis dam, that has a height of $91 \mathrm{~m}$.

\section{Materials and methods}

The MQI evaluation provides a first phase of initial analysis and subdivision in homogeneous reaches, analyzing existing information and remote sensing data by GIS, and a subsequent application phase of the evaluation procedure (Rinaldi et al., 2013 ). In this work, during the river network segmentation, various tools and scripts were implemented to reduce the application time , as the semi-automatic calculation of the indices needed to define the degree of confinement. During the second phase we analyzed the information derived from the first phase, and field surveys were made in 42 reaches with the support of the evaluation forms in order to define the geomorphic functionality, artificiality and channel adjustments for each reach.

\section{General setting and segmentation}

The initial setting and river network segmentation into relatively homogeneous reaches, considering the valley form, slope, flow and sediment load conditioning (Brierley and Fryirs, 2005) was carried in GIS project (ArcGIS 10, ESRI ${ }^{\circledR}$ ) in which it was implemented a database with the following metadata:

- Digital color orthophotos for the years 2000, 2003, and 2006 available in Web Map Service mode on the National Geoportal (http://www.pcn.minambiente.it/GN/)

- Digital Terrain Model (DTM) in "ascii" format, downloaded from the Regional Geoportal (http://idt.regione.veneto.it/app/metacatalog/ index?deflevel=165) and subsequently converted to raster with $5 \mathrm{mX} 5 \mathrm{~m}$ cell.

- Regional Technical Maps (CTR Veneto Region, from Geoportal)

- Regional Physiographic Units Map available from site of Agency for Environmental Protection and Prevention of Veneto, ARPAV (http://www.arpa.veneto.it/temi-ambientali/suolo)

- Regional Geolitological Map (downloaded from Regional Geoportal)

- Artificial Intervention Database (watershed management and torrent control structures) of the Belluno Province, provided by the Regional Hydrological Service.

These last metadata are organized according to types of structures, in different shapefiles that report essential information (eg. year of construction, geometric dimensions, etc.) for both the first as well as the second phase of the MQI evaluation.

The catchment area definition and the identification of the synthetic hydrographic network was made with the Arc Hydro Tools (ESRI ${ }^{\circledR}$ ) setting the blue lines threshold value $=16$ ha. From the DTM the Slope and Exposure Maps were derived. This geospatial information jointly the 2006 orthophotos were utilized for the photo-interpretation (Figure 2) and editing of active channel and alluvial plain (which is defined as the maximum width of the investigation river region). This editing work has been carried out throughout the river network from the $4^{\text {th }}$ to $6^{\text {th }}$ order (Horton-Strahler classification; Strahler, 1964).

The segmentation methodology was based on the MQI protocol application (Rinaldi et al., 2012), but has been applied to a slightly different steps sequence and have been implemented some semi-automatic GIS processes. Initially it was carried out a first segmentation (editing of lines) considering the physiographic units, hydrological discontinuities (from hydro elaboration and artificial intervention database), relevant changes in channel width and alluvial plan width (obtained from

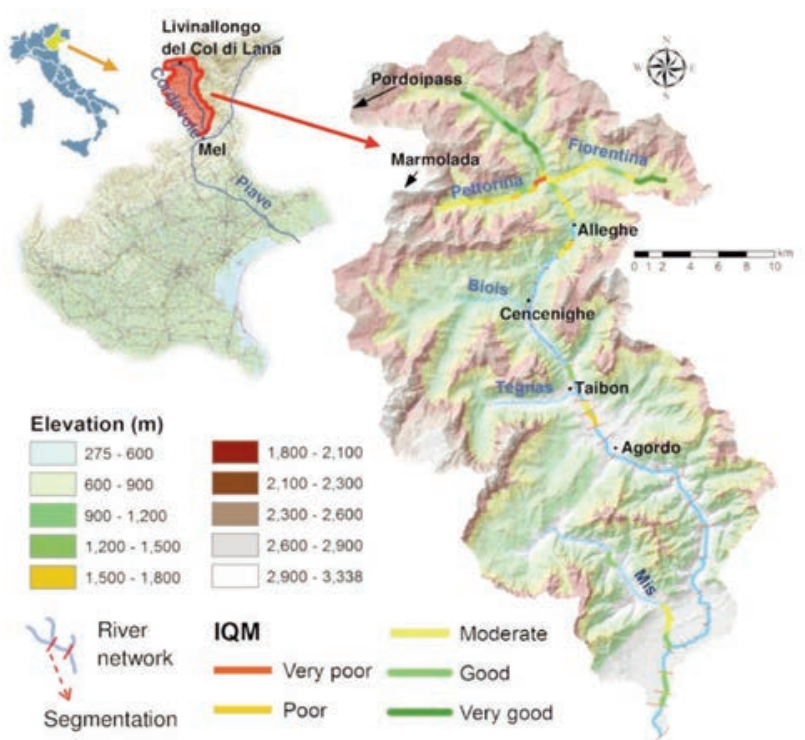

Figure 1. Map of the Cordevole basin, hydrograph segmentation and MQI evaluation results. 
photo-interpretation), bed slope (slope map), and variations in geolitology. The active channel and alluvial plain shapes has been subdivided into various polygons with the segmentation lines intersection. The outer area of these polygons (buffer of $20 \mathrm{~m}$ ) was intersected with the slope map, and has been calculated automatically the percentage of banks directly in contact with the hillslopes, identified as the terrain portions with a slope greater than $20^{\circ}$ (Figure 2). In other words, it has been defined for each reaches the "degree of confinement". With other semi-automatic procedures was calculated the polygons area and perimeter and then the ratio between the alluvial plain width and the channel width for each reaches, called the "confinement index". Putting together these two indices could be computed rather quickly the lateral confinement (for more details on the classification see Rinaldi et al., 2012). Eventually, according to this lateral confinement, appropriate adjustments have been carried on the initial division, and then we proceeded in the definition of river morphology taking into account the specific Italian Alpine context (e.g., Lenzi et al., 2000).

\section{Evaluation procedure}

After the segmentation phase, for each identified reach were summarized data and information needed to apply the evaluation procedure. The field surveys were made in the period August 2012 - May 2013 with the support of the evaluation forms. 31 reaches of the upper part of the Cordevole ( $76 \%$ of reaches identified in segmentation phase) were analyzed and 11 other reaches representative of the downstream area. The water conditions during the measurements were of low flow and no significant flood events in prior periods. As required by the protocol different indices of geomorphological functionality, artificiality, and only for two reaches (channel width greater than $30 \mathrm{~m}$ ) the channel adjustments, were analyzed. The evaluation of the 28 indicators was complete with the application MQI evaluation forms, which can be of two types, one for confined channels, and one for semi-confined and unconfined (Rinaldi et al., 2013). The number and type of indicators are not the same in these two evaluation forms.

The main attention was paid to the analysis in the continuity (lateral and longitudinal) of river processes, channel morphological conditions and vegetation. Most of the applied indices were evaluated thanks to the information obtained during the first phase of general settings and segmentation. Three classes are generally defined for each indicator evaluating with a score of 0 in the case of absence or negligible presence of alteration, intermediate alteration score of 2-3, and highest alteration score 5-6. In cases of extremely dense and dominant presence of artificial elements are awarded additional points of alteration.

\section{Results}

The segmentation phase has identified 62 reaches of $4^{\text {th }}, 33$ of $5^{\text {th }}$, and 37 of $6^{\text {th }}$ order (132 in total). For each of them, through the GIS analysis, segment length, average width of the active channel and alluvial plain, average slope, and drainage area were obtained. Furthermore, the degree of confinement and confinement index (Table 1) were calculated. All these data have been included in the GIS project database. The results show that the average length of river segments obtained is between $951 \mathrm{~m}$ ( $5^{\text {th }}$ order) and $1347 \mathrm{~m}$ ( $6^{\text {th }}$ order $)$. The average width of the active channel is strictly linked to the reach order, and changes from $15 \mathrm{~m}$ ( $4^{\text {th }}$ order $)$, to $31 \mathrm{~m}$ ( $5^{\text {th }}$ order $)$ and $88 \mathrm{~m}$ for the

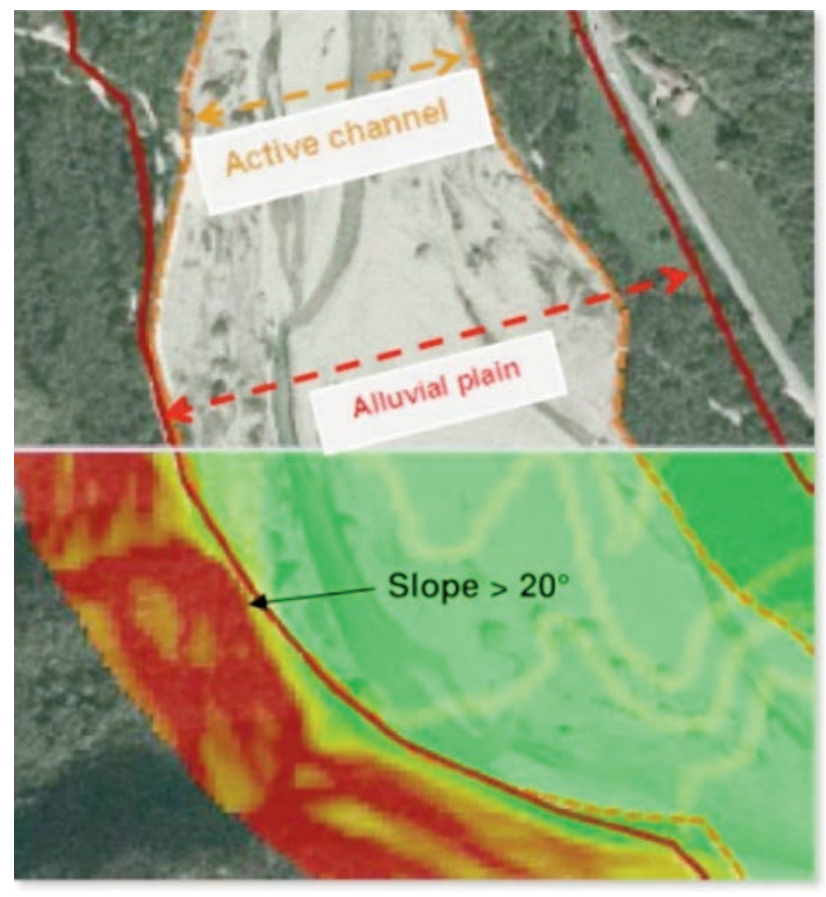

Figure 2. Segmentation phase and calculation of the indices of confinement.

Table 1. Characteristics of the reaches obtained in the segmentation phase of MQI protocol.

\begin{tabular}{|c|c|c|c|c|c|c|c|c|c|c|}
\hline $\begin{array}{l}\text { Stream } \\
\text { order }\end{array}$ & $\begin{array}{l}\text { Reaches } \\
\text { identified }\end{array}$ & & $\begin{array}{l}\text { Length } \\
\text { (m) }\end{array}$ & $\begin{array}{l}\text { Width } \\
\text { Alluvial plain } \\
\text { (m) }\end{array}$ & $\begin{array}{l}\text { Active channel } \\
\text { (m) }\end{array}$ & $\begin{array}{l}\text { Elevation } \\
\text { (m.a.s.l.) }\end{array}$ & $\begin{array}{c}\text { Degree } \\
\text { of confinament }\end{array}$ & $\begin{array}{l}\text { Confinament } \\
\text { Index }\end{array}$ & $\begin{array}{c}\text { Mean } \\
\text { Channel } \\
\text { Slope } \\
(\mathrm{m} / \mathrm{m})\end{array}$ & $\begin{array}{c}\text { Drainage } \\
\text { Area } \\
\left(\mathrm{km}^{2}\right)\end{array}$ \\
\hline \multirow[t]{3}{*}{6 th } & \multirow[t]{3}{*}{37} & Mean & 1347 & 218 & 88 & 583 & 0.2 & 2.4 & 0.016 & 522 \\
\hline & & Max & 2923 & 920 & 310 & 1000 & 0.7 & 4.3 & 0.109 & 844 \\
\hline & & Min & 465 & 40 & 26 & 278 & 0.0 & 1.1 & 0.0004 & 222 \\
\hline \multirow[t]{3}{*}{ 5th } & \multirow[t]{3}{*}{33} & Mean & 951 & 68 & 31 & 758 & 0.3 & 2.3 & 0.035 & 81 \\
\hline & & Max & 1940 & 188 & 86 & 1115 & 0.8 & 5.0 & 0.078 & 163 \\
\hline & & Min & 404 & 21 & 12 & 325 & 0.0 & 1.1 & 0.007 & 35 \\
\hline \multirow[t]{3}{*}{ 4th } & \multirow[t]{3}{*}{62} & Mean & 1124 & 24 & 15 & 1091 & 0.3 & 1.6 & 0.091 & 27 \\
\hline & & Max & 1907 & 72 & 48 & 1634 & 0.9 & 2.5 & 0.259 & 70 \\
\hline & & Min & 345 & 6 & 5 & 425 & 0.0 & 1.1 & 0.011 & 8 \\
\hline
\end{tabular}


reach of $6^{\text {th }}$ order (Table 1). The degree of confinement, calculated with semi-automatic GIS methods has an average value of 0.2-0.3 with a maximum of 0.9 ( $90 \%$ of channel in contact with the slopes) in the smaller streams (Figure 3). The confinement index (relationship between the width of the alluvial plain and bankfull) is in general directly proportional to the stream order, with average values of between 1.6 and 2.4 (Figure 3), although higher values are observed in the case of $5^{\text {th }}$ order

The application of MQI evaluation forms has required about 3 hours of field surveys for each reach analyzed, for a total of 15 days of activity. 10 reaches of $6^{\text {th }}$ order ( $27 \%$ of this order reaches identified in segmentation phase), 14 of $5^{\text {th }}$ order $(42 \%)$ and 18 of $4^{\text {th }}$ order $(27 \%)$ were analyzed. The results derived from the application of various indices have been organized in the summary sheets (one for each reaches) that contains tables with the general settings (location, confinement and morphology), scores attributed to each indicator and the calculation of MQI and the corresponding class quality. This data are summarized in Table 2 that contains the name of the river, reach order, the class of confinement, Morphological Alteration Index (MAI), MQI and the quality class represented with different. The MQIs obtained were also implemented in the GIS database from which it was obtained a layout summary (Figure 1) where the quality classes (with different colors) for each reach analyzed can be observed. On average, the lower values of MQI are observed in the Pettorina reaches and in $4^{\text {th }}$ order reaches, as can be seen from the box plot in Figure 4. The distribution of MQI seems more linked to the collectors that the river order. These results show
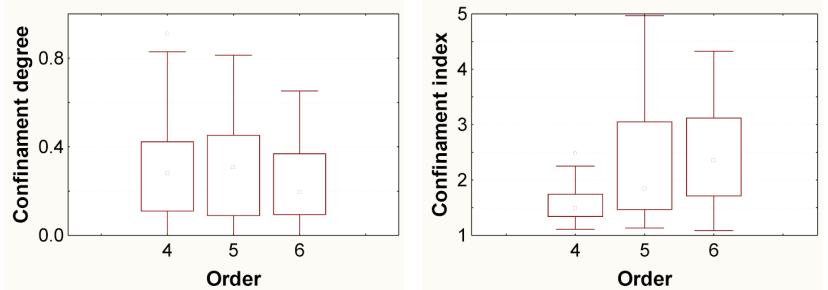

Figure 3. Degree and index of confinement in relation to order for the 137 reaches identified in segmentation phase of MQI protocol. The square within each box indicates the median value, box ends are $25^{\text {th }}$ and $75^{\text {th }}$ percentiles, whiskers are the 10th and 90th percentiles, and dots are outliers.
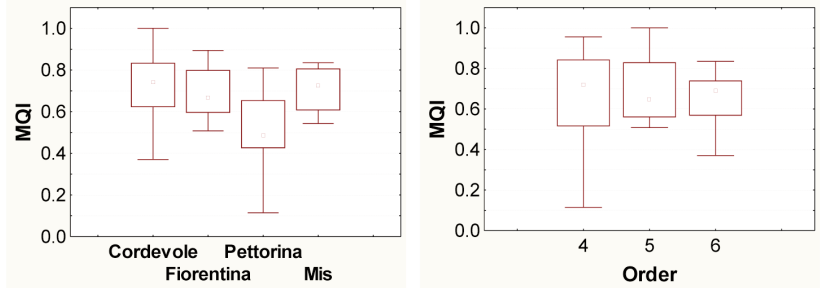

Figure 4. MQI evaluation results of the different streams and in relation to order for the 42 reaches analyzed. The square within each box indicates the median value, box ends are 25 th and 75 th percentiles, whiskers are the

Table 2. Morphological Quality Index results for the 42 reaches analyzed. Contains the name of the river, reach order, the class of confinement (Conf. class) and Morphological Alteration Index (MAI). The quality class is represented with different colors in MQI index cells: red, very poor; orange, poor; yellow, moderate; light green, good; dark green, very good. Look at the Figure 1 for the distribution into the river network of morphological quality class evaluated.

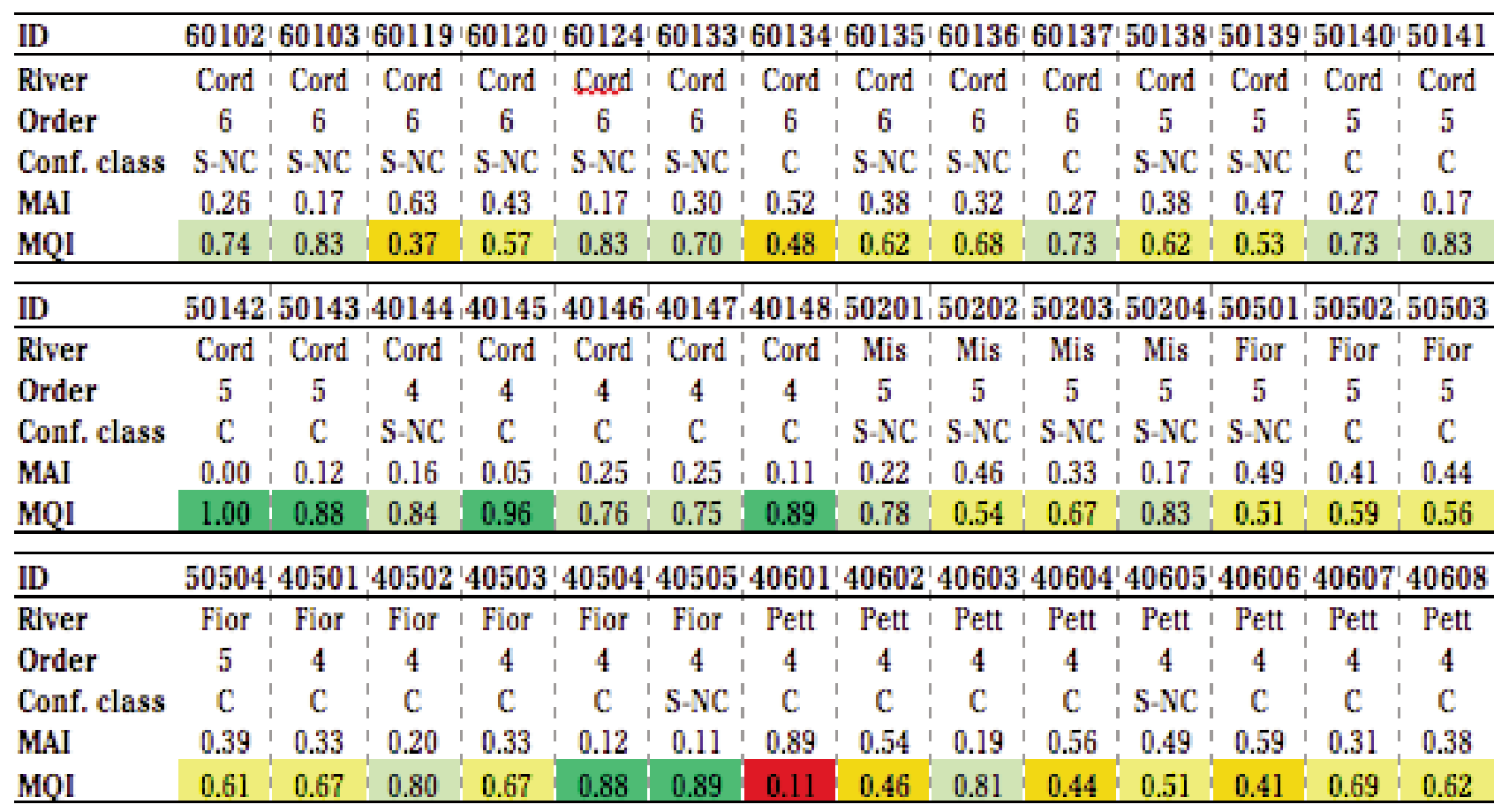

Cord, Cordevole; Fior, Fiorentina; Pett, Pettorina. C, confined; S-NC, semi-confined/unconfined. 


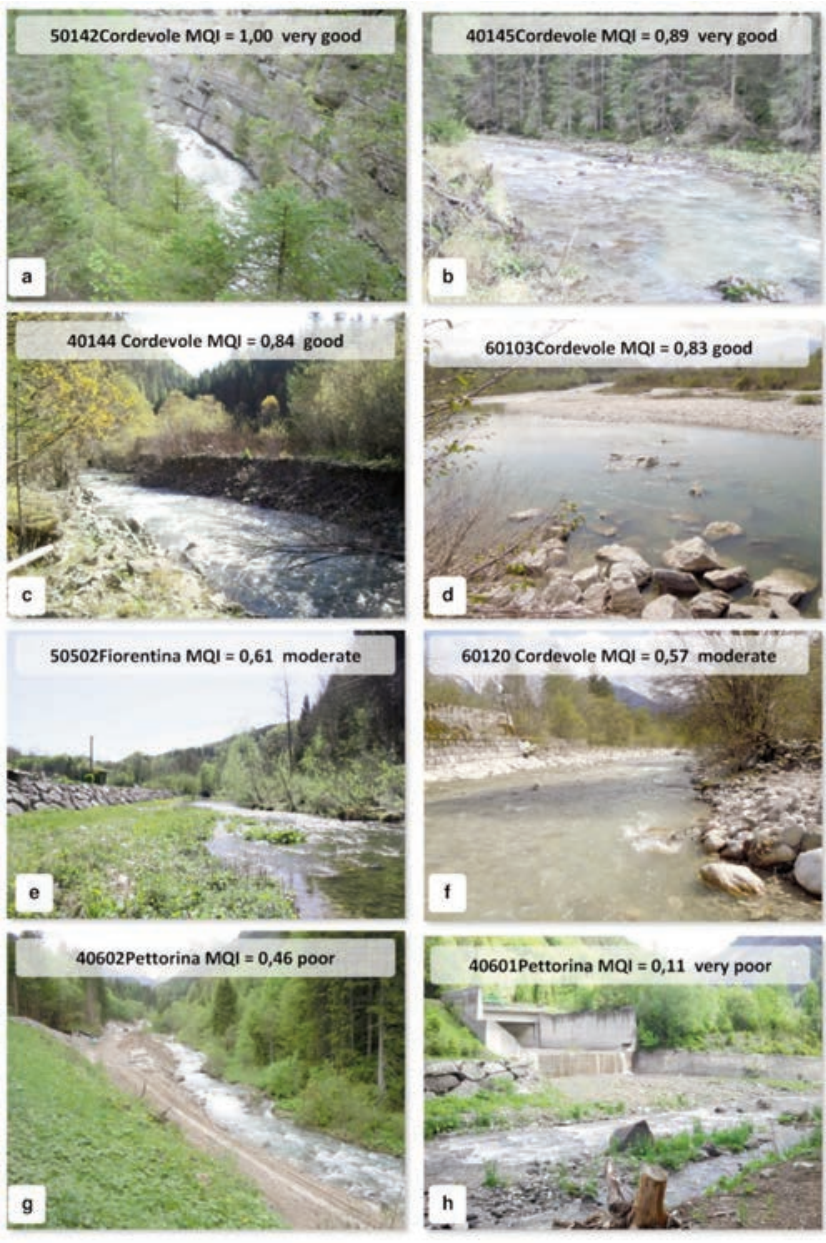

Figure 5. Photos of some reaches evaluated and MQI results.

that $48 \%$ of the reaches analyzed have a good or high quality, and these are mainly located in the High Cordevole or in the less hydrographic network (four examples shown in Figure 5a, 5b, 5c, 5d). 38\% present a moderate quality, and in particular different reaches of the Fiorentina, Cordevole from Caprile to Alleghe and Pettorina (Figure 5e 5f). Only $14 \%$ is in poor or very poor quality, such as the Pettorina reach immediately upstream of the confluence with the Cordevole (Figure 5e 5f ).

\section{Discussion and final remarks}

This work shows the successfully use, in a dolomite basin (Torrente Cordevole, Bl), of the new MQI protocol evaluation (Rinaldi et al., 2013). The implementation of some semi-automatic GIS tools has allowed us to greatly speed up the first phase of the general setting and segmentation. It was also possible to determine in the laboratory, some indicators of alteration, in particular those that have a flood plain or basin scale application. Some limitations or problems arising during this first phase can be summarized as follows: i) the need of very good capacity of GIS analysis and editing; ii) limit of spatial analysis linked both the quality of the DTM and images, and the strong disturbance (shadows, vegetation, narrow valleys): in our case study it is seen that the hydrographic network lower of the fourth order are difficult to ana- lyze; iii) need for a complete and updated of Artificial Intervention Database. In the analyzed area there are gaps in this database also of great works, such as the dam of Mis.

The second phase of indicators implementation has highlighted a low availability of some information necessary for the evaluation, such as the management of artificial structures and river clear-cut operation, and information of morphometric changes of the last 50 years of the great reaches. Some indicators are extremely simplified as shown by the MQI authors (Rinaldi et al., 2103) and there is a strong subjectivity in the scoring of the indices in relation to the experience and training of the operators.

The sub-reaches that have the greatest degree of morphological alteration present i) poor connectivity between hillslopes and river corridor, mainly caused by the presence of roads, that is very important for the natural input from the slopes of sediment and large wood; ii) absence of vegetation in the river corridor, almost always as a result of human alteration, that is functional to a range of geomorphic processes; iii) presence of artificial elements, particularly the bedload interception structures in the catchment, bank protection along the reach, and the removal of sediment, large wood and vegetation, already highlighted in Rigon et al., (2012a). A partial restoration of these reaches could be implemented by converting the old interception structures in new constructions designed by the criteria of natural engineering. In addition, it would be desirable to carry out the analysis of priorities, and implementing intervention only where really necessary, possibly with low-impact structures (e.g. wood retention structures with rope nets or rakes).

\section{References}

Brierley G.J., Fryirs K.A., 2005. Geomorphology and River Management: Applications of the River Style Framework. Blackwell, Oxford, UK . $398 \mathrm{pp}$.

European Commission, 2000. Directive 2000/60/EC of the European Parliament and of the Council of 23 October 2000 Establishing a Framework for Community Action in the Field of Water Policy. Official Journal L 327, 22/12/2000, Brussels, Belgium. 73 pp.

European Commission, 2007. Directive 2007/60/EC of the European Parliament and of the Council of 23 October 2007 on the Assessment and Management of Flood Risks. Official Journal L 288/27, 6/11/2007, Brussels, Belgium. 8 pp.

Gurnell A, Surian N, Zanoni L. 2009. Multi-thread river channels: a perspective on changing European alpine river systems. Aquatic Sciences 71: 253-265.

Lenzi M.A., D’Agostino V., Sonda D. (2000) - "Ricostruzione morfologica e recupero ambientale dei torrenti", + CD rom "Le morfologie d'alveo dei corsi d'acqua alpini”, 208 pp., Bios, Cosenza, (ISBN 887740-302-0).

Liébault F., Piégay H. 2001. Assessment of channel changes due to longterm bedload supply decrease, Roubion River, France. Geomorphology 36: 167-186.

Moretto J., Rigon E., Mao L., Picco L., Delai F., Lenzi M.A. 2012. Medium- and short-term channel and island evolution in a disturbed gravel bed river (Brenta River, Italy). Journal of Agricultural Engineering. Vol. 43, 4; 176-188. DOI: 10.4081/jae.2012.e27.

Picco L., Mao L., Rigon E., Moretto J., Ravazzolo D., Delai F., Lenzi M.A. 2012 An update of the sediment fluxes investigation in the Rio Cordon (Italy) after 25 years of monitoring. Journal of Agricultural Engineering. Vol. 43, 3; 108-113; doi: 10.4081/jae2012e17

Rigon E., Comiti F., Lenzi M.A. 2012a. Large wood storage in streams of the Eastern Italian Alps and the relevance of hillslope processes. 
Water Resources Research VOL. 48, W01518, doi:10.1029/2010WR009854

Rigon E., Moretto J., Mao L., Picco L., Delai F., Ravazzolo D., Lenzi M.A. \& Kaless G, 2012b. Thirty years of vegetation cover dynamics and planform changes in the Brenta River (Italy): implications for channel recovery; IAHS Publication N. 356, pp. 178-186; ISSN 01447815.

Rinaldi M., Surian N., Comiti F., Busettini M., 2013. A method for the assessment and analysis of the hydromorphological condition of Italian streams: The Morphological Quality Index (MQI). Geomorphology 180-181: 96-108.

Rinaldi M., Surian N., Comiti F., Bussettini M., 2012. Guidebook for the
Evaluation of Stream Morphological Conditions by the Morphological Quality Index (MQI). Version 1.1. 85 pp Istituto Superiore per la Protezione e la Ricerca Ambientale, Roma. ISBN: 978-88-448-0487-9.

Strahler, A. N. 1964. Quantitative geomorphology of drainage basins and channel networks, Handbook of Applied Hydrology, section 4IIV. T. Chow, McGraw-Hill, New York.

Surian N., Ziliani L., Comiti F., Lenzi M.A., Mao L. 2009. Channel adjustments and alteration of sediment fluxes in gravel-bed rivers of north-eastern Italy: Potentials and limitations for channel recovery. River Research and Applications 25: 551-567. 